Nurhapisah : Pengelolaan Lahan berdasarkan Indeks Bahaya Erosi dan Ekonomi Sub DAS Pacangkuda

Hulu Palopo

\title{
PENGELOLAAN LAHAN BERDASARKAN INDEKS BAHAYA EROSI DAN EKONOMISUB DAS PACANGKUDA HULU KOTA PALOPO
}

\author{
(Land Management Based on Erosion and Economic Hazard Index of Hulu \\ Pacangkuda Watershed Palopo City) \\ Nurhapisah $^{1}$, Amir Tjoneng ${ }^{2}$, Saida $^{2}$ \\ ${ }^{1)}$ Mahasiswa Magister Agroekoteknologi PPs-UMI, Makassar \\ Email : nurhapisahbungari@gmail.com \\ 2) Jurusan Agroteknologi Fakultas Pertanian, UMI
}

\begin{abstract}
The main problem of damage to land resources in the Pacangkuda Hulu watershed is caused by erosion. Conversion of forest areas into cultivation areas and land management that does not apply the right soil conservation techniques is the cause. The purpose of this study was to determine the extent of erosion, tolerated erosion (TSL), erosion hazard index (IBE), land management patterns and farming income in the Upper Pacangkuda watershed. This study uses a survey method of USLE method erosion prediction analysis. The results showed that the highest erosion was in shrub land use, which amounted to 696.424 tons / ha / year, while the lowest erosion was found in primary forest land use which was 2,350 tons / ha / year. The highest tolerated erosion was found in mixed plantation land use of 29.758 tons / ha / yr and the lowest was in shrub land use of 10.588 tons / ha / year. The highest erosion hazard index is found in shrub land use of 65.788 tons / ha / year with very high IBE criteria while the lowest erosion hazard index is secondary forest land use of 0.107 tons / ha / year with low IBE criteria. Land management and agrotechnology which are alternatives are Multiple cropping agriculturesystems with gulud and bangku terrace conservation actions. Income from farming based on Sayogyo is still categorized as poor to very poor with income ranging from Rp. 9,074,076, / up to Rp. 12,799,764 / year / year. Compared with income based on Palopo City of Rp. 2,200,000, the farming income is still relatively low
\end{abstract}

Keywords : Erosion, USLE, Erosion Hazard index, soil conservation

PENDAHULUAN

Permasalahan utama kerusakan sumber daya lahan di daerah aliran sungai disebabkan oleh erosi. Erosi merupakan proses terlepasnya butiran tanah dari induknya disuatu tempat dan terangkutnya material tersebut oleh gerakan air atau angin kemudian diiukuti dengan pengendapan material yang terangkut di tempat yang lain (Suripin, 2004). Terjadinya erosi menyebabkan kerusakan lahan yang meliputi kerusakan pada sifat fisik, kimia dan biologi tanah. seperti: air sungai menjadi keruh, pendangkalan sungai dan waduk, penggerusan tebing sungai, pencucian hara tanah, menurunnya produktifitas lahan, menipisnya solum tanah, dan meluasnya lahan kritis, yang pada akhirnya berujung pada terjadinya degradasi lahan. 
Nurhapisah : Pengelolaan Lahan berdasarkan Indeks Bahaya Erosi dan Ekonomi Sub DAS Pacangkuda Hulu Palopo

Dewasa ini DAS Pacangkuda perencanaan dan pengaturan penggunaan mencerminkan kondisi yang kurang baik. lahan lahan mewujudkan penggunaan lahan Konversi kawasan hutan menjadi areal yang optimal diharapkan kerusakan tanah budidaya sebagai salah satu penyebabnya.

Hasil penelitian oleh Dinas Kehutanan dan Perkebunan Kota Palopo (2012) menunjukkan bahwa luas lahan kritis di kawasan DAS Pacangkuda adalah 2.598,18 ha atau $39,09 \%$ dari total $6.646,66$ luas DAS Pacangkuda secara keseluruhan. Lebih lanjut Dishut (2012) melaporkan, peran penting DAS Pacangkuda semakin berkurang karena kualitas lingkungan sekitar DAS Pacangkuda yang terus menurun, hal tersebut ditandai dengan tingkat bahaya erosi yang mencapai 141, 29 ton/ha/tahun dan sedimentasi mencapai 17,92 ton/ha/tahun

Pemanfaatan lahan yang tidak sesuai kemampuannya akan menyebabkan kerusakan tanah dan lingkungan yang lebih parah. Tanpa adanya perencanaan penataan dan pengaturan penggunaan DAS kearah yang optimal memungkinkan kerusakan tanah dan lingkungan DAS secara keseluruhan akan lebih parah dimasa mendatang dan semakin meluasnya lahan yang tidak produktif. Untuk itu perlu dan lingkungan dapat ditekan seminimal mungkin dan pemanfaatan ekonomi diperoleh secara maksimal (Tjoneng, 1999).

Tujuan penelitian ini adalah Menganalisis besarnya erosi di Sub DAS Pacangkuda Hulu, Menganalisis erosi yang dapat ditoleransikan di Sub DAS Pacangkuda Hulu, Menganalisis Indeks bahaya Erosi (IBE) di Sub DAS Pacangkuda Hulu, Menganalisis pola penggunaan lahan di Sub DAS Pacangkuda Hulu, Menganalisis pendapatan dan usaha tani secara akual dan setelah pemilihan alternatif penggunaan lahan Sub DAS Pacangkuda Hulu

\section{METODE PENELITIAN}

Penelitian mengenai "Pengelolaan Lahan Berdasarkan Indeks Bahaya Erosidan Ekonomi Sub DAS Pacangkuda Hulu Kota Palopo" dilaksanakan di Sub DASPacangkuda Hulu Kota Palopo mencakup Kecamatan Sendana, Kecamatan Mungkajang dan Kecamatan Wara Bara. Alat yang di gunakan dalam penelitian antara lain, GPS, Kompas, Ring Sampel, 
Nurhapisah : Pengelolaan Lahan berdasarkan Indeks Bahaya Erosi dan Ekonomi Sub DAS Pacangkuda Hulu Palopo

Palu, Papan, Parang, Pisau, Meteran Roll, Tali rapiah,Plastik transparan, Kertas Label, Kamera, Alat Tulis Menulis dan Seperangkat Komputer dengan Program GIS (Arcview, ArGis 10.3). Bahan yang digunakan yaitu peta penggunaan lahan, peta jenis tanah, SRTM (peta kelas lereng), dan peta batas DAS. Sedangkan data yang digunakan adalah data curah hujan

\section{Pengumpulan Data}

\section{Tahap Pesiapan}

Tahap ini merupakan tahap studi kepustakaan, yaitu meneliti dan mengkaji pustaka yang telah ada tentang keadaan lahan di lokasi penelitian serta data sekunder lainnya.

\section{Tahap Survey Pendahuluan}

Survey pendahuluan bertujuan untuk mempersiapkan survey utama yang akan dilakukan kemudian. Selain menyiapkan urusan administrasi, survey pendahuluan juga bertujuan melakukan orientasi di daerah penelitian untuk memperoleh gambaran menyeluruh tentang kondisi lapangan dan mengindetifikasi permaslahan yang mungkin didapat di lapangan.

\section{Pembuatan peta Unit Lahan}

Peta unit lahan adalah tumpang tindih (overlay) dari peta topografi (kelas lereng), peta jenis tanah dan peta penggunaan lahan dengan menggunakan perangkat komputer dan program ArGis 10.3.

4. Tahap Survey Utama

a. Pengambilan sampel tanah untuk nilai erodibilitas tanah (K). Pengambilan sampel mewakili setiap jenis tanah.

b. Pengamatan vegetasi yang ada dan agroteknologi yang di terapkan di lapangan.

c. Pengumpulan data sosial ekonomi dilakukan dengan metode wawancara langsung dan kuisioner. Responden dipilih secara acak dari populasi petani lahan kering secara kombinasi dan tidak mempunyai pekerjaan sampingan. Intensitas samplingditentukan 10 orang dari tiap-tiap lingkungan yangterdapat di lokasi penelitian dengan pertimbangan dapat mewakili populasi yang ada di daerah penelitian.

5. Analisis laboratorium.

Sampel tanah yang didapatkan dilapangan selanjutnya dianalisis di laboratorium untuk mendapatkan nilai 
Nurhapisah : Pengelolaan Lahan berdasarkan Indeks Bahaya Erosi dan Ekonomi Sub DAS Pacangkuda Hulu Palopo

Faktor erodibilitas tanah. Besarnya erodibilitas tanah dipengaruhi oleh tekstur, struktur, permeabilitas dan bahan organik.

\section{Analisis Data}

\section{Prediksi Erosi}

Prediksi erosi dihitung dengan menggunakan persamaan umum kehilangan tanah yaitu Metode Wischmeier (1978) atau USLE (universal soil loss equation) sebagai berikut:

$$
\mathrm{A}=\mathrm{R} \times \mathrm{K} \times \mathrm{LS} \times \mathrm{C} \times \mathrm{P}
$$

Dimana:

A=Banyaknya tanah yang tererosi (ton/ha/tahun)

$\mathrm{R}=$ Erosivitas hujan adalah kemampuanhujan untuk mengerosi tanah. Nilai erosivitas hujan pada penelitian ini menggunakan data curah hujan selama 10 tahun terakhir (2006-2017). Dihitung berdasarkan persamaan Leanvin (1975 dalamBols, 1978) dalam Hardjowigeno (2007).

$\mathrm{C}=$ Nilai faktor pengelolaan tanaman (C) merupakan nisbah antara tanah yang hilang pada pengelolaan lahan tertentu degan tanah yang hilang tanpa tanaman

$\mathrm{P}=$ Nilai faktor $\mathrm{P}$ ditentukan berdasarkan kondisi di lapangan dimana tidak hanya tindakan konservasi tanah secara mekanik tetapi juga berbagai usaha yang bertujuan mengurangi erosi tanah.

$$
\mathrm{RM}=2,21 \text { (Rain) }{ }^{1,36}
$$

Dimana :

RM=Erosovitas Hujan bulan (Rain): Curah hujan bulan $(\mathrm{cm})$
$\mathrm{K}=$ Besarnya nilai $\mathrm{K}$ ditentukan oleh tekstur, struktur, kandungan bahan organik, permeabilitas tanah dan kemantapan struktur tanah. Nilai erodibiltas (K) dihitung dengan menggunaakan persamaan Wischmeier dan Smith (1978) :

$$
\begin{aligned}
100 \mathrm{~K}= & 1,292\left[2,1 \mathrm{M}^{1,14}(10)(12-\mathrm{a})+\right. \\
& 3,25(\mathrm{~b}-2)+2,5(\mathrm{c}-3)]
\end{aligned}
$$

\section{Dimana :}

$\mathrm{M}=$ Persentase pasir sangat halus dan debu (diameter $0,1-\quad 0,05$ dan $0,05-0,02 \mathrm{~mm}$ ) $\mathrm{x}$ (100\%liat)

$\mathrm{a}=$ Persentase Bahan Organik

$\mathrm{b}=$ Kode struktur tanah

$\mathrm{c}=$ Kelas permeabilitas tanah

LS=Faktor panjang dan kemiringan lereng dalam penelitian ini menggunakan data ketetapan nilai LS berdasarkan Departemen Kehutanan

Tabel 1. Penilaian Kelas Lereng

\begin{tabular}{cccc}
\hline \hline Kelas & Lereng $(\%)$ & Keterangan & Nilai LS \\
\hline I & $0-8$ & Datar & 0.40 \\
II & $8-15$ & Landai & 1.40 \\
III & $15-25$ & Agak curam & 3.10 \\
IV & $25-40$ & Curam & 6.80 \\
V & $>40$ & Sangat curam & 9.20 \\
\hline \hline
\end{tabular}

Sumber : RTL-RLKT DepartemenKehutanan, 1995.

2. Erosi yang dapat ditoleransikan-TSL (Tolerabel Soil Loss)

Erosi yang ditoleransikan dihitung berdasarkan pendekatan Hammer (1981) dalam Asdak (2002) berdasarkan atas kedalaman ekivalen tanah dan jangka waktu kelestarian sumberdaya tanah yang 
Nurhapisah : Pengelolaan Lahan berdasarkan Indeks Bahaya Erosi dan Ekonomi Sub DAS Pacangkuda Hulu Palopo

diharapkan. Erosi yang dapat ditoleransikan

(TSL) dihitung dengan rumus :

$$
\mathrm{TSL}=\frac{K E \cdot F K}{U G T}
$$

\section{Dimana :}

TSL=Erosi yang dapat ditoleransikan (ton/ha/thn)

$\mathrm{KE}=$ Kedalaman Efektif Tanah $(\mathrm{mm})$

FK = Faktor Kedalaman Sub-Ordo Tanah

UGT=Umur Guna Tanah (untuk kepentingan pelestarian di gunakan 400 tahun).

3. Menentukan Indeks Bahaya Erosi

Indeks Bahaya Erosi (IBE) dapat ditentukan berdasarkan persamaan Wood dan Dent (1983) dalam Hardjowigeno (2007) beriku :

$$
\mathrm{IBE}=\frac{\text { Jumlah tanah yang tererosi }(\mathrm{A})}{\text { Jumlah Erosi yang toleransikan (TSL) }}
$$

\section{Dimana :}

$\mathrm{A}=$ Erosi yang diperkirakan menurut USLE (ton/ha/tahun)

TSL=Erosi yang dapat ditoleransikan (ton/ha/tahun)

Indeks dikelompokkan dalam berbagai kategori seperti pada Tabel 2 .

Tabel 2. Klasifikasi Indeks Bahaya Erosi (Hammer,1981)

\begin{tabular}{ccc}
\hline No & $\begin{array}{c}\text { Nilai Indeks Bahaya } \\
\text { Erosi }\end{array}$ & Harkat \\
\hline \hline 1 & $<1.0$ & Ringan \\
2 & $1.01-4.0$ & Sedang \\
3 & $4.01-10$ & Tinggi \\
4 & $>10.01$ & Sangat Tinggi \\
\hline \hline
\end{tabular}

Sumber : Arsyad, 2010
4. Pengelolaan Tanaman dan Agroteknologi Penentuan pengelolaan tanaman dan Agroteknologi dilakukan dengan cara mengubah nilai $\mathrm{C}$ (tanaman) dan $\mathrm{P}$ (tindakan konservasi). Bila nilai erosi (A) lebih besar dari erosi yang dapat ditoleransikan (TSL) maka akan dilakukan skenario (perubahan). Maka akan dilakukan perhitungan kembali sehingga nilai erosi (A) akan lebih kecil atau sama dengan erosi yang dapat ditoleransikan (TSL). Ini dimaksudkan untuk menentukan pola tanaman apa yang sesuai dan penerapan tindakan konservasi tanah apa yang sesuai pada lahan tersebut.

5. Analisa Biaya dan Pendapatan Petani sekitar DAS Pacangkuda Hulu

Pendapatan bersih merupakan selisih antara penerimaan (pendapatan kotor) dengan biaya (pengeluaran total). Pendapatan bersih dapat dihitung menggunakan Rumus:

$$
\mathrm{NR}=\mathrm{TR}-\mathrm{TC}
$$

Dimana ;

NR(Net Return) $=$ Pendapatan Bersih $(\mathrm{Rp})$ $\mathrm{TR}($ TotalRevenue $)=$ TotalPenerimaan $(\mathrm{Rp})$

TC $($ Total Cost $)=$ Total Biaya yang terdiri atas biaya benih, pupuk, pestisida,tenaga kerja, penyusutan alat dan sewa lahan (Pengeluaran) (Rp) 
Nurhapisah : Pengelolaan Lahan berdasarkan Indeks Bahaya Erosi dan Ekonomi Sub DAS Pacangkuda Hulu Palopo

\section{HASIL DAN PEMBAHASAN}

\section{Prediksi Erosi Metode USLE}

Berdasarkan perhitungan beberapa parameter pendugaan erosi pada berbagai penggunaan lahan (hutan primer, hutan sekunder, perkebunan campuran, peranian lahan kering, pertanian lahan kering campur semak dan semak/belukar), maka nilairataan laju erosi pada berbagai penggunaan lahan disajikan pada Tabel 3.

Berdasarkan Tabel 3 tersebut diatas, dapat dilihat bahwa penggunaan lahan hutan primer mempunyai nilai laju erosi paling rendah diantara berbagai penggunaan lahan di Sub DAS Pacangkuda Hulu 2,350 ton/ha/tahun. Sedangkan untuk nilai laju erosi terbesar terlihat pada penggunaan lahan semak/belukar yakni 696,424 ton/ha/tahun. Tingginya laju erosi yang terjadi pada satuan penggunaan lahan berkaitan dengan penutupan lahannya yaitu vegetasi yang memiliki kerapatan tajuk yang rendah dibandingkan hutan yang memiliki tajuk dan kerapatan yang tinggi serta tidak adanya tindakan konservasi pda lahan tersebut. Hal ini sesuai dengan pendapat Asyad (2010) menyatakan bahawa ketinggian tajuk dan kerapatan tajuk akan melindungi permukaan tanah terhadap besarnya pengaru esosivitas butiran-butiran hujan dalam mengurangi tumbukan yang sampai ke permukaan tanah.

\section{Erosi Yang Dapat Ditoleransikan - TSL (Tolereble Soil Loss)}

Perhitungan nilai erosi yang dapat ditoleranasikan ditentukan berdasarkan kedalaman efektif tanah, nilai faktor kedalaman sub order tanah, bobot isi tanah, dan umur guna tanah. Perbandingan nilai prediksi erosi dan TSL pada berbagai penggunaan lahan di lokasi penelitian disajikan pada Tabel 3.

Tabel tersebut menunjukkanbahwa nilai erosi yang dapat ditoleransikan di Sub DAS Pacangkuda Hulu dimulai dari 10,588 ton/ha/thn sampai dengan 29,758 ton/ha/thn Hal ini menunjukkan bahwa erosi yang terjadi di Sub DAS Pacangkuda Hulu sudah melebihi batas erosi yang dapat ditoleransikan sehingga dapat mengaggu produktivitas tanaman. Penentuan batas erosi yang dapat dioleransikan sangat penting diketahui agar dapat menurunkan laju erosi yang terjadi pada suatu lahan baik pertanian maupun non pertanian. Hal ini sesuai yang dikemukakan Kartasapoertra, dkk (1988) menyatakan bahwa penentuan 
Nurhapisah : Pengelolaan Lahan berdasarkan Indeks Bahaya Erosi dan Ekonomi Sub DAS Pacangkuda Hulu Palopo

batas erosi yang diperbolehkan sangat penggunaan lahan hutan primer dengan nilai penting bagi usaha-usaha pertanian sebesar 0,107 dan penggunaan hutan sehingga diketahui cara-cara pengelolaan sekunder 0,402 . Hal ini menunjukkan lahan yang tepat untuk mengurangi erosi bahawa kawasan hutan di Sub DAS yang melewati batas yang diperbolehkan Pacangkuda Hulu perlu dipertahankan. sehingga kelangsungan usaha pertanian Sedangkan pada penggunaan lahan berjalan dengan baik.

\section{Indeks Bahaya Erosi (IBE)}

Indeks bahaya erosi ditentukan dengan membandingkan jumlah tanah yang tererosi dan besar erosi yang ditoleransikan. Tujuan menentukan tingkat bahaya erosi yaitu untuk mengetahui sejauh mana erosi yang terjadi akan membahayakan kelestarian produktivitas tanah.Nilai Indeks Bahaya erosi di Sub DAS Pcangkuda Hulu dapat dilihat pada Tabel 3.

Tabel 3 menunjukkan kriteria indeks perkebunan campuran menunjukkan kriteria rata-rata indeks bahaya erosi pada harkat yang sangat tinggi yaitu >10,417. Pada penggunaan lahan pertanian lahan kering menunjukkan indeks bahaya erosi pada harkat sangat tinggi dengan nilai rata-rata 13,370, Pada penggunaan pertanian lahan kering bercampur semak menunjukkan indeks bahaya erosi pada harkat sangat tinggi dengan nilai rata-rata 39,023 dan penggunaan semak/belukar menunjukkan indeks bahaya.

bahaya erosi harkat rendah yaitu $<1,0$ pada

Tabel 3. Rekapan Rataan Indeks Bahaya Erosi di Berbagai Penggunaan Lahan Sub DAS Pacangkuda

\begin{tabular}{cccccccc}
\hline \hline & $\begin{array}{c}\text { Erosi } \\
\text { (ton/ha/th) }\end{array}$ & $\begin{array}{c}\text { TSL } \\
\text { (ton/ha/th) }\end{array}$ & KET. & $\begin{array}{c}\text { Indeks } \\
\text { Bahaya } \\
\text { Erosi }\end{array}$ & Kriteria IBE & ha & $\%$ \\
\hline $\mathrm{Hp}$ & 2,35 & 22,031 & Tidak Rusak & 0,107 & Ringan & $1.796,463$ & 45,53 \\
$\mathrm{Hs}$ & 8,65 & 21,506 & Tidak Rusak & 0,402 & Ringan & 574,626 & 14,56 \\
$\mathrm{Pk}$ & 309,98 & 29,758 & Rusak & 10,417 & Sangat Tinggi & 519,022 & 13,15 \\
$\mathrm{Pl}$ & 202,22 & 15,125 & Rusak & 13,370 & Sangat Tinggi & 29,503 & 0,75 \\
$\mathrm{Pc}$ & 654,42 & 16,784 & Rusak & 39,023 & Sangat Tinggi & 345,305 & 8,75 \\
$\mathrm{~S}$ & 696,42 & 10,588 & Rusak & 65,778 & Sangat Tinggi & 680,705 & 17,25 \\
\hline
\end{tabular}

Sumber : Data sekunder setelah diolah dan Hasil Analisis SIG, 2018

Keterangan : PL = Penggunaan Lahan, Hp= Hutan Primer, Hs = Hutan Sekunder, Pk=Perkebunan Campuran, $\mathrm{Pl}=$ Pertanian Lahan Kering, $\mathrm{Pc}=$ Pertanian lahan kering campur semak, $\mathrm{S}=\mathrm{Semak} /$ Belukar. 
Nurhapisah : Pengelolaan Lahan berdasarkan Indeks Bahaya Erosi dan Ekonomi Sub DAS Pacangkuda Hulu Palopo

Erosi pada harkat sangat tinggi agroteknologi optimal yang disesuaikan dengan nilai rata-rata 65,778. Hal ini dengan kondisi ekonomi maupun sosial menunjukkan bahwa erosi yang terjadi di budaya petani setempat sehingga terbentuk Sub DAS Pacangkuda lebih besar pertanian yang berkelanjutan. Pola tanam dibandingakan dengan erosi yang dan pengelolaan tanah yang ditoleransikan yang dapat membahayakan direkomendasikan dapat dilihat pada Tabel kelestarian produktivitas lahan sehingga 4

perlu memperhatikan vegetasi dan Tabel 4 menunjukkan bahwa dengan penerapan tindakan konservasi tanah dan penerapan pola tanam perkebunan dengan air.

penutupan rapat dan penerapan teknik konservasi teras gulud, teras bangku di Sub

\section{Pola Tanam dan Agroteknologi}

DAS Pacangkuda Hulu, maka besarnya

Berdasarkan hasil pengamatan di lokasi penelitian, pola tanam yang diterapkan oleh petani adalah pola tanam yang tidak tetap dan tidak teratur dimana penanaman tanaman sampingan disisipkan diantara tanaman utama.

Penentukan alternatif pola tanam dan agroteknologi di Sub DAS Pacangkuda Hulu dilakukan dengan cara membandingan erosi yang terjadi dengan besarnya erosi yang dapat ditoleransikan (TSL). Diupayakan hasil prediksi erosi lebih kecil atau sama dengan erosi yang ditoleransikan dengan mengsimulasikan nilai $\mathrm{C}, \mathrm{P}$ atau $\mathrm{CP}$ sehingga diperoleh alternatif pola tanam dan erosi yang terjadi lebih kecil atau sama dengan nilai erosi yang ditoleransikan. Hal ini sesuai pendapat Bukhari, dkk (2014) dalam Pasaribu, dkk (2017) yang menyatakan untuk mengantisipasi atau meminimalisirkan laju erosi dilahan tersebut perlu dilakukan upaya praktek konservasi untuk menekan laju erosi seperti melakukan penanaman dengan lajur memotong lereng atau searah dengan garis kontur. Selain itu juga bisa dilakukan pemilihan jenis tanaman yang memiliki nilai faktor (C) yang kecil sehingga dapat memperkecil laju erosi. 
Nurhapisah : Pengelolaan Lahan berdasarkan Indeks Bahaya Erosi dan Ekonomi Sub DAS Pacangkuda Hulu Palopo

Tabel 4. Alternatif Pola Tanam dan Agroteknologi pada Berbagai Penggunaan Lahan di Sub DAS Pacangkuda Hulu

\begin{tabular}{ccccccccc}
\hline \hline PL & $\begin{array}{c}\text { Nilai } \\
\text { CP }\end{array}$ & $\begin{array}{c}\text { Erosi } \\
\text { Aktual } \\
\text { (ton/ha/thn) }\end{array}$ & $\begin{array}{c}\text { TSL } \\
\text { (ton/ha/thn) }\end{array}$ & $\begin{array}{c}\text { Pola Tanam } \\
\text { Dan } \\
\text { Agroteknologi }\end{array}$ & $\begin{array}{c}\text { Nilai } \\
\text { CP }\end{array}$ & $\begin{array}{c}\text { Erosi } \\
\text { Perbaikan } \\
\text { (ton/ha/thn) }\end{array}$ & IBE & $\begin{array}{c}\text { Kriteria } \\
\text { IBE }\end{array}$ \\
\hline \hline Pk & 0,2 & 309,98 & 29,758 & PK. Rapat + TB & 0,004 & 21,698 & 0,163 & Ringan \\
$\mathrm{Pt}$ & 0,2 & 202,22 & 15,125 & PK. Rapat + TB & 0,004 & 14.155 & 0,120 & Ringan \\
$\mathrm{Pc}$ & 0,4 & 654,42 & 16,784 & $\begin{array}{c}\text { PK. Rapat + TB } \\
\text { Sengon disertai }\end{array}$ & 0,004 & 12,837 & 0,590 & Ringan \\
$\mathrm{S}$ & 0,3 & 696,42 & 10,588 & $\begin{array}{c}\text { Semak + TG } \\
\text { seman }\end{array}$ & 0,00168 & 3,900 & 0,115 & Ringan \\
\hline
\end{tabular}

Keterangan : PL = Penggunaan Lahan, Hp= Hutan Primer, Hs = Hutan Sekunder, Pk=Perkebunan Campuran, $\mathrm{Pl}=$ Pertanian Lahan Kering, $\mathrm{Pc}=$ Pertanian lahan kering campur semak, $\mathrm{S}=$ Semak/Belukar

Analisis Biaya dan Pendapatan Usaha tani mengetahui pendapatan yang diperoleh

Berdasarkan pola tanam aktual yang petani dalam satu bulan. Hasil analisis biaya diterapkan oleh petani setempat, maka perlu dan pendapatan petani untuk pola lahan dilakukan analisis finansial untuk aktual pada kebun campuran, pertanian mengetahui pendapatan yang diperoleh lahan kering dan pertanian lahan kering petani dalam satu bulan. Hasil analisis biaya bercampur semak disajikan pada Tabel 5 . dan pendapatan petani untuk pola lahan aktual pada kebun campuran, pertanian lahan kering dan pertanian lahan kering bercampur semak disajikan pada Tabel 5 .

Tabel 5 menunjukkan bahwa rata-rata pendapatan bersih untuk pola tanam Kebun campuran dengan luas $1 \mathrm{Ha}$ adalah $\mathrm{Rp}$ 1.011.554,-,-kk/ha/bln atau setara dengan Rp 12.138.648,- kk/ha/thn. Pendapatan.

Tabel 5. Hasil analisis biaya dan Pendapatan untuk pola tanam Aktual pada Penggunaan Lahan di SubDAS PacangkudaHulu

\begin{tabular}{ccc}
\hline PenggunaanLahan & Pola Tanam & $\begin{array}{c}\text { Pendapatan bersih } \\
(\mathbf{R} \mathbf{p} / \mathbf{K K} / \mathbf{b l n})\end{array}$ \\
\hline \hline $\mathrm{Pk}$ & Tanaman tahunan & $1.011 .554,-$ \\
$\mathrm{Pt}$ & Tanaman tahunan & $1.011 .554,-$ \\
$\mathrm{Pc}$ & Tanaman tahunan dan Semak & $760.925,-$ \\
\hline \hline
\end{tabular}

Sumber : Hasil Analisis, 2018

Keterangan $\mathrm{PK}=$ Perkebunan Campuran, $\mathrm{Pt}=$ Pertanian Lahan Kering, $\mathrm{Pc}=$ Pertanian Lahan Kering Campur Semak,S $=$ Semak/Belukar. 
Nurhapisah : Pengelolaan Lahan berdasarkan Indeks Bahaya Erosi dan Ekonomi Sub DAS Pacangkuda Hulu Palopo

Bersih pada pola lahan kering campur semak adalah Rp760.925,-/bln atau setara dengan $\mathrm{Rp} 9.131 .100,-\mathrm{kk} / \mathrm{ha} / \mathrm{thn}$

Jika analisis kelayakan berdasarkan standar kebutuhan fisik minimum dan hidup layak ditentukan berdasarkan kebutuhan beras per kepala keluarga dan harga beras yang berlaku di daerah tersebut. Maka pendapatan bersih ini lebih kecil (termasuk kategori miskin hingga miskin sekali ) dari garis kemiskinan perkotaan yang didasarkan pada beras yaitu $480 \mathrm{~kg}$, dimana harga beras pada lokasi penelitian Rp 10.000/kg. berdasarkan rata-rata jumlah tanggungan keluarga 4 orang, maka diperoleh standar kemiskinan $\operatorname{Rp} 19.200 .000, / \mathrm{kk} / \mathrm{thn}$ atau setara dengan Rp 4.800.000,/org/thn. Dan jika dibandingkan dengan pendapatan berdasarkan upah minimum Kota Palopo yakni Rp 2.200.000,-/org/bln atau setara Rp 26.400.000,-/org/thn maka pendapatan petani masih relatif rendah yaitu dibawah UMR Kota Palopo.

Untuk itu diperlukan perbaikan pola tanam dan agroteknologi pada pola tanam perkebunan campuran dan pertanian lahan kering campur semak. pola yang diterapkan harus menekan erosi dan meningkatkan pendapatan petani, sehingga didapat nilai erosi yang lebih kecil atau sama dengan dari erosi yang ditoleransikan agar produktivitas lahan dapat dipertahankan yang nantinya akan terjadi peningkatan pendapatan usaha tani diatas upah minimum kota palopo.

Hasil analisis finansial untuk pola tanam dan agroteknologi yang yang sebaiknya diterapkan pada kebun campuran, pertanian lahan kering, dan pertanian lahan kering campur semak. Maka hasil analisis pendapatan untuk pola tanam alernatif pada kebun campuran, pertanian lahan kering, pertanian lahan kering campur semak disajikan pada Tabel 6.

Table 6. Hasil analisis pendapatan untuk berbagai tipe alternatif pola tanam di Sub DAS Pacangkuda Hulu

\begin{tabular}{clc}
\hline \hline Tipe Petani & \multicolumn{1}{c}{$\begin{array}{c}\text { Pola } \\
\text { Tanam Alternatif }\end{array}$} & $\begin{array}{c}\text { Pendapatan bersih } \\
\text { (Rp/KK/bln) }\end{array}$ \\
\hline Tipe A & Durian + Kakao & $6.080 .705,-$ \\
Tipe B & Durian + Cengkeh & $5.306 .603,-$ \\
Tipe C & Durian + Kakao+ Duku & $9.856 .671,-$ \\
Tipe D & Durian + Cengkeh + Duku & $9.082 .569,-$ \\
Tipe E & Sengon+ Kakao & $5.508 .208,-$ \\
\hline
\end{tabular}

Sumber : Data sekunder setelah diolah, 2018 

Nurhapisah : Pengelolaan Lahan berdasarkan Indeks Bahaya Erosi dan Ekonomi Sub DAS Pacangkuda Hulu Palopo

Berdasarkan hasil analisis biaya dan pendapatan untuk berbagai tipe alternatif pola tanam pada di Sub DAS Pacangkuda hulu pada Tabel 6 terlihat bahwa pola tanam tipe A hingga tipe $\mathrm{C}$ memperoleh pendapatan bersih diatas gasri kemiskinan perkotaan yang didasarkan pada beras yaitu $480 \mathrm{~kg}$ dengan tanggungan 4 orang dan dibandingkan dengan pendapatan berdasarkan upah minimum regional Kota Palopo Rp 2.200.000,- maka pendapatan petani masih lebih besar.

\section{KESIMPULAN}

1. Besarnya erosi yang terjadi di Sub DAS Pacangkuda sangat beragam yaitu pada penutupan lahan hutan primer sebesar 2,350 ton/ha/tahun, hutan sekunder sebesar 8,646 ton/ha/tahun, perkebunan campuran sebesar 309.976 ton/ha/tahun, pertanian lahan kering sebesar 202,221 ton/ha/tahun, pertanian lahan kering bercampur semak sebesar 654,951 ton/ha/tahun, serta semak/belukar sebesar 696,424 ton/ha/tahun.

2. Besarnya erosi yang dapat ditoleransikan di Sub DAS Pacangkuda yaitu pada penutupan lahan hutan primer sebesar 22.031 ton/ha/tahun hutan sekunder sebesar 21.506 ton/ha/tahun, perkebunan campuran sebesar 29.758 ton/ha/tahun, pertanian lahan kering sebesar 15.125 ton/ha/tahun, pertanian lahan kering bercampur semak sebesar 16.784 ton/ha/tahun, dan semak/belukar sebesar 10.588 ton/ha/tahun

3. Indeks bahaya erosi yang terjadi pada berbagai penggunaan lahan di Sub DAS Pacangkuda hulu menunjukkan kriteria rendah hingga sangat tinggi. Kriteria rendah pada penggunaan lahan hutan primer dan sekunder sedangkan untuk kriteria sangat tinggi yaitu pada penggunaan lahan perkebunan campuran, pertanian lahan kering, pertanian lahan kering bercampur semak serta semak/belukar

4. Pola pengelolaan lahan yang menjadi alternatif pada berbagai penggunaan lahan di Sub DAS Pacangkuda Hulu adalah

a. Pengelolaan tanaman dan agroteknologi yang menjadi alternatif pada penggunaan lahan perkebunan campuran adalah pola tanam perkebunan rapat dengan 
Nurhapisah : Pengelolaan Lahan berdasarkan Indeks Bahaya Erosi dan Ekonomi Sub DAS Pacangkuda Hulu Palopo

tindakan konservasi Teras Bangku Baik

b. Pengelolaan tanaman dan agroteknologi yang menjadi alternatif pada penggunaan lahan pertanian lahan kering adalah pola tanam perkebunan rapat dengan tindakan konservasi Teras Bangku Baik

c. Pengelolaan tanaman dan agroteknologi yang menjadi alternatif pada penggunaan lahan pertanian lahan kering bercampur dengan semak adalah perkebunan rapat dengan tindakan konservasi Teras Bangku Baik

d. Pengelolaan tanaman dan agroteknologi yang menjadi alternatif pada penggunaan lahan semak adalah penanaman sengon campur semak dengan tindakan konservasi teras gulud

5. Pendapatan usaha tani Sub DAS Pacangkuda Hulu adalah:

a. Pendapatan Aktual, berdasarkan Sajogyo dikategorikan Miskin hingga miskin sekali dimana pendapatanya berkisar $\mathrm{Rp}$ 9.131.100,-/kk/thn hingga $\mathrm{Rp}$ 12.138.648,-/kk/thn. Dibandingkan dengan pendapatan bersadarkan UMR Kota Palopo, maka pendapatan usaha tani masih relatif rendah

b. Pendapatan Setelah perbaikan, berdasarkan Sajogyo dikategorikan Miskin pendapatanya berkisar $\mathrm{Rp}$ 63.679.236-/kk/thn hingga $\mathrm{Rp}$ 118.280.052,-/kk/thn. Dibandingkan dengan pendapatan bersadarkan UMR Kota Palopo, maka pendapatan usaha tani masih lebih besar/diatas pendapatan UMR Kota Palopo.

\section{DAFTAR PUSTAKA}

Asdak, C., 2002. Hidrologi dan Pengelolaan Daerah Aliran Sungai. Gadjah Mada University Press: Yogyakarta.

Arsyad, S., 1989. Konservasi Tanah dan Air. Penerbit. IPB/IPB Pros. Cetakan ketiga. Darmaga, Bogor , 2010. Konservasi Tanah dan Air. Penerbit. IPB/IPB Pros. Cetakanketiga. Darmaga, Bogor

Departemen Kehutanan, 2009. Peraturan Mentri Kehutanan Nomor P32/MENHUT-II/2009. Tentang Tata Cara penyusunan Perencanaan teknik Rehabilitasi Hutan dan Lahan Daerah 

Nurhapisah : Pengelolaan Lahan berdasarkan Indeks Bahaya Erosi dan Ekonomi Sub DAS Pacangkuda Hulu Palopo

Aliran Sungai (RTKRHL-DAS). Jakarta 1995. Rencana Teknik Lapangan Rehabilitasi Lahan dan Konservasi Tanah Sub DAS KAO. Sub Balai Rehabilitasi lahan dan Konservasi Tanah Maluku

Hardjowigeno, W., Sarwono. 2007. Evaluasi Kesesuaian Lahan dan Perencanaan Tataguna Lahan. Gadjah Mada University Press. Yogyakarta.

Kartasapoetra, 1988. Teknologi Konservasi Tanah dan Air. Rineka Cipta: Jakarta.

Pasaribu, Parlin Hotmartua, 2018. Kajian Tingkat Bahaya Erosi Untuk Arahan Konservasi tanah pada berbagai Tipe
Penggunaan Lahan di Kecamatan Merdeka Kabupaten Karo.Jurnal Geografi Vol. 10 No.1. Program Stidi Pengelolaan Sumberdaya Alam dan Lingkungan Pasacasarjana USU Medan.

Suripin, 2004. Pelestarian Sumber Daya Tanah dan air. Penerbit Andi: Yogyakarta.

Tjoneng, Amir, 1999. Kajian Optimalisasi Penggunaan Lahan di Daerah Tangkapan Datara Kawasan Bili-Bili Sulawesi Selatan. Disertasi Program Pascasarjana Institut Pertanian Bogor. Bogor. 